\title{
IRRIGAÇÃO LOCALIZADA E A INCIDÊNCIA DO BICHO-MINEIRO DO CAFÉ
}

Adriano Augusto de Paiva Custódio ${ }^{1}$, Jair Campos Moraes ${ }^{1}$, Alexandre Roberto Canino ${ }^{2}$, Manoel Alves de Faria ${ }^{3}$, Mirian de Lourdes Oliveira e Silva ${ }^{3}$, Anselmo Augusto de Paiva Custódio ${ }^{4}$

${ }^{1}$ Departamento de Fitopatologia da UFLA, C.P.3037, CEP 37200-000, Lavras, MG.

${ }^{2}$ Departamento de Entomologia da UFLA, C.P.3037, CEP 37200-000, Lavras, MG. E-mail: jcmoraes@ den.ufla.br

${ }^{3}$ Departamento de Engenharia da UFLA, C.P 3037, CEP 37200-000, Lavras, MG.

${ }^{4}$ Departamento de Produção Vegetal da UNESP, Campus de Jaboticabal, CEP 14.883-390, Jaboticabal, SP.

\section{RESUMO}

O objetivo neste trabalho foi avaliar a influência do manejo de irrigação por gotejamento na incidência do bicho-mineiro-do-cafeeiro (BMC), Leucoptera coffeella (Guérin-Menéville 1842) (Lepidoptera: Lyonetiidae), durante dois anos. O estudo foi realizado em cafeeiro adulto da cultivar Acaiá MG-1474. O delineamento experimental foi em blocos ao acaso, com quatro repetições e cinco manejos de irrigação, determinados conforme as épocas do ano e da disponibilidade de água no solo. A avaliação do BMC foi realizada pelo método não destrutivo, coletando-se aleatoriamente 10 folhas do terço mediano ao ápice por planta, nas oito plantas por parcela, sendo cinco ramos em cada face de exposição da planta ao sol. Dessa forma, foram amostradas 160 folhas por parcela, sendo $80 \mathrm{em}$ cada face de exposição da planta. Foi observada interação entre manejos de irrigação e faces de exposição da planta e influência isolada do fator épocas de avaliação. No tratamento sem irrigação e no manejo em que se irrigou durante todo o ano sempre que o teor da água disponível no solo atinge $25 \%$ da disponibilidade total de água na camada de 0-40 cm, foi constatada menor incidência do BMC para a face de exposição das plantas voltadas ao sul. Houve ainda, maior incidência do inseto-praga na época de menor pluviosidade, entre os meses de abril e outubro, porém com baixos índices, inferior a 5\%.

Palavras-chave: Água de irrigação, Leucoptera coffeella, MIP

\section{DRIP IRRIGATION AND THE INCIDENCE OF THE COFFEE LEAF-MINER}

\section{ABSTRACT}

The aim of this work was to evaluate the influence of drip irrigation management on the incidence of the coffee leaf miner (CLM), Leucoptera coffeella (Guérin-Menéville 1842) (Lepidoptera: Lyonetiidae) during two years. The experimental design was randomized blocks with four replications and five irrigation managements, determined according to the seasons and availability of water in the soil. The evaluation was conducted by the CLM non-destructive method, collecting at random 10 branches of the middle third apex per plant in eight plants per plot, five branches on each side of the plant exposure to the sun. Thus, we sampled 160 leaves per plot, 80 on each face exposure of the plant. We observed the interaction between irrigation management and face exposure of the plant and single influence of the evaluation periods factor. In the treatment without irrigation and the management that is irrigated throughout the year whenever the content of available soil water reaches $25 \%$ of the total availability of water in the layer of 0-40 cm one observed, lower incidence of LM to face exposure of plants facing south. There was also a higher incidence of the insect pest at the lowest rainfall period between the months of April and October, but at low population level, less than 5\%.

Keywords: Water irrigation, Leucoptera coffeella, IPM 


\section{INTRODUÇÃO}

O Brasil é o maior produtor mundial de café, com participação na safra 2010/2011 estimada em 47,2 milhões de sacas de $60 \mathrm{~kg}$. Além disso, o país é o segundo maior mercado consumidor. Assim, a cultura do cafeeiro tem grande importância sócio-econômica para o Brasil, sendo o estado de Minas Gerais responsável por cerca de 50\% da produção nacional, localizando-se na região sul a maior área plantada. Ainda, $25 \%$ da produção nacional são provenientes de apenas 240 mil ha de áreas irrigadas, ou seja, $10 \%$ do total (Agrianual, 2011).

O cafeeiro foi tradicionalmente cultivado em áreas com condições pluviométricas favoráveis ao seu crescimento e desenvolvimento. Entretanto, essa cultura vem sendo cada vez mais incorporada em áreas com escassez hídrica. A irrigação suplementar nessas localidades tem mostrado significativos incrementos de produção, mesmo em regiões com curtos períodos de deficiência hídrica (Lima et al., 2008; Coelho et al., 2009). Conforme Meireles et al. (2001), uma cultura quando irrigada fica submetida a um microclima diferenciado em relação ao cultivo em regime de sequeiro, resultando em características peculiares do cultivo em relação aos aspectos fitotécnicos, fisiológicos e fitossanitários. Assim, para cafeeiros irrigados, devem ser realizados estudos visando relacionar níveis e manejos de aplicação de água e variações apresentadas com relação aos aspectos de insetos-praga, como o bicho-mineiro do café (BMC) (Meireles et al., 2001; Custódio et al., 2009), que podem ocasionar significativas perdas na lavoura (Souza et al., 1998).

O BMC é uma micromariposa apresentando $6,5 \mathrm{~mm}$ de envergadura das asas, que são brancas na parte dorsal com uma pontuação escura na extremidade.
Durante o dia, o inseto-praga se oculta na parte inferior das folhas tendo hábitos crespuscular-noturnos. $\mathrm{O}$ inseto sofre metamorfose completa, passando pelas fases de ovo, lagarta, pupa e adulta, sendo a fase larval a prejudicial ao cafeeiro (Souza et al., 1998). As lesões causadas pelo bichomineiro nas folhas do cafeeiro são responsáveis por reduzir a área foliar e, consequentemente a capacidade fotossintética das plantas, causando desfolha, o que leva à redução da produção e da longevidade dos cafeeiros (Gallo et al., 2002). A ocorrência do bicho-mineiro está relacionada a fatores climáticos como a temperatura e a chuva; condições da própria lavoura como o arejamento; e a presença de inimigos naturais como parasitóides, predadores e entomopatógenos (Reis et al., 1998).

Muitos são os equipamentos de irrigação utilizados para suprir a demanda de água das plantas, destacando-se o sistema localizado, tipo gotejamento, e por aspersão, tipo pivô central. Cada sistema de irrigação apresenta vantagens e desvantagens, porém Santinato et al. (2008) citam como o mais indicado para a cafeicultura irrigada, o tipo gotejamento. Entre as estratégias de manejo integrado de pragas, a manipulação do ambiente natural da praga e/ou dos seus inimigos naturais pode ser efetiva na redução da população do inseto-praga (Gravena, 1983). Conforme Zambolim et al. (2007), o BMC é desfavorecido pela irrigação, além de ser mais severo em regiões e períodos de seca. Entretanto, os autores citam que em áreas onde se pratica a irrigação, como no cerrado mineiro e no oeste baiano, é comum ocorrer alta incidência de insetos-praga, em razão das altas temperaturas.

Dessa forma, determinar o ambiente favorável para a ocorrência de pragas permitirá conhecer métodos de controle que visem à redução de perdas na lavoura, gerando informações importantes sobre o manejo eficaz da água de irrigação. Isso 
contribuirá com a redução de impactos ambientais, pela correta utilização da água de irrigação e inseticidas na agricultura. Assim, o objetivo deste trabalho foi verificar a incidência do BMC, em lavoura irrigada pelo método localizado tipo gotejamento, sob diferentes manejos de irrigação durante dois anos.

\section{MATERIAL E MÉTODOS}

O trabalho foi realizado em área do Departamento de Engenharia da Universidade Federal de Lavras, situado à latitude $21^{\circ} 13^{\prime} 46^{\prime}$ ' Sul, longitude 4458'32" Oeste e altitude média de 908 metros. O solo da área foi classificado como Latossolo Vermelho Escuro, de textura muito argilosa. A cultivar estudada foi a Acaiá MG-1474, plantada em março de 1997, no espaçamento adensado de 3,00 m entre linhas e $0,60 \mathrm{~m}$ entre plantas, ocupando área útil de $1,8 \mathrm{~m}^{2}$ planta $^{-1} \mathrm{e}$ densidade populacional de 5.555 plantas $\mathrm{ha}^{-1}$, sendo recepada em outubro de 2004 e irrigada desde o plantio (Custódio, 2009).

O delineamento experimental foi o de blocos casualizados, com cinco tratamentos primários (manejos de irrigação) e quatro repetições, conforme realizado por Custódio (2009). Cada parcela foi constituída por 10 plantas, considerando-se oito plantas úteis para avaliação da variável resposta, possuindo uma planta de cada extremidade como bordadura. Os tratamentos primários foram os seguintes: $A=$ sem irrigação (testemunha); $\mathrm{B}=$ irrigação $\mathrm{o}$ ano todo sempre que o teor da água disponível no solo (AD) atingia $25 \%$ da disponibilidade total de água (DTA) na camada de 0-40 cm; C= irrigação o ano todo sempre que $\mathrm{AD}<75 \%$ DTA na camada de $0-40 \mathrm{~cm} ; \mathrm{D}=$ irrigação o ano todo, quando, em janeiro, fevereiro, março, julho, outubro, novembro e dezembro $\mathrm{AD}<75 \%$ DTA e em abril, maio, junho, agosto e setembro, quando $\mathrm{AD}<25 \%$ DTA na camada de 0-40 cm; $\mathrm{E}=$ irrigação em abril, maio, junho, agosto e setembro, quando $\mathrm{AD}<75 \%$ DTA na camada de $0-40$ $\mathrm{cm}$.

Foi utilizado o sistema de irrigação por gotejamento, de acionamento manual. A água foi distribuída às plantas por meio de gotejadores autocompensantes (150 a 400 $\mathrm{kPa}$ ) distanciados em $0,40 \mathrm{~m}$ entre si, proporcionando uma faixa molhada de 3,6 $\mathrm{m}^{2}$ com pressão de serviço de $300 \mathrm{kPa}$ (30 mca) e vazão de 4,0 $1 \mathrm{~h}^{-1}$. A água utilizada foi proveniente de uma barragem situada a $350 \mathrm{~m}$ da área experimental, onde se encontra uma unidade de bombeamento (Custódio, 2009).

Todos os tratamentos, exceto a testemunha, receberam adubação por meio de fertirrigação. $O$ adubo foi aplicado durante os meses de outubro a março, em três a quatro parcelamentos. O tratamento não irrigado recebeu adubação manual na mesma época. A quantidade de adubo aplicado foi determinada mediante análise química do solo e previsão de safra futura. A dose e o parcelamento de adubação foram iguais para todos os tratamentos. As adubações foram complementadas conforme o laudo da análise química de folha. As interpretações das análises químicas de folha e de solo seguiram a recomendação de Ribeiro et al. (1999).

Foram executados, durante a condução do experimento, os tratos culturais sempre que necessário. Sendo assim, foram realizadas somente aplicações de fungicidas (epoxiconazol + piraclostrobina e epoxiconazol) visando o controle de doenças, além do controle de mato. Fez-se a coleta dos dados climatológicos a uma distância de $570 \mathrm{~m}$ do local do experimento. Os dados corresponderam aos valores diários, obtidos da média de pelo menos três das quatro observações meteorológicas, de acordo com o Tempo Médio de Greenwich. $\mathrm{O}$ período de monitoramento foi compreendido conforme a mesma época da 
avaliação do BMC. Os dados obtidos foram das variáveis temperatura máxima, média e mínima $\left({ }^{\circ} \mathrm{C}\right)$, insolação (horas/dia), umidade relativa do ar (\%) e precipitação pluviométrica (mm).

As avaliações da população do BMC foram realizadas no período compreendido entre março de 2009 e março de 2011, totalizando 24 avaliações em 24 meses, com intervalos médios de 31 dias entre as avaliações. No esquema fatorial, foram consideradas como época (tratamentos secundários) as médias das avaliações correspondentes a cada mês do ano (janeiro a dezembro), para uma análise média de dois anos da incidência do BMC.

Conforme Custódio et al. (2009), a avaliação foi realizada considerando todas as folhas minadas, intactas e dilaceradas, pelo método não destrutivo, feito na própria planta. Para isso, foram amostradas ao acaso 10 ramos do terço mediano ao ápice por planta, sendo 5 ramos para a face de exposição voltada ao hemisfério norte e 5 ramos para a face de exposição voltada ao hemisfério sul (tratamentos terciários). Foram analisadas duas folhas localizadas no terceiro e/ou quarto par de folhas por ramo, nas 8 plantas por parcela, o que totalizou 160 folhas amostradas por parcela.

Os dados médios de folhas minadas coletados foram previamente transformados em $\log (x+0,5)$. A análise de variância e o teste de comparação de médias (Tukey) foram realizadas a $5 \%$ de probabilidade, com auxílio do programa AgroEstat Versão 1.0 (Barbosa \& Maldonado Júnior, 2010). Foram realizadas as análises de variância do BMC em função dos diferentes manejos de irrigação, face de exposição da planta e épocas (meses) de avaliação.

\section{RESULTADOS E DISCUSSÃO}

Houve influência significativa dos diferentes fatores estudados na incidência do bicho-mineiro do cafeeiro. Registrou-se interação $(p \leq 0,05)$ entre manejos de irrigação e face de exposição da planta e influência isolada $(p \leq 0,01)$ do fator épocas de avaliação (Tabela 1).

Mesmo com baixos índices do insetopraga, inferiores a $3 \%$, foram registradas tendências de menores incidências do BMC no manejo de irrigação 'A' (testemunha; sem irrigação) e no manejo ' $B$ ' em que se irrigou durante todo o ano sempre que o teor da água disponível no solo atingia $25 \%$ da disponibilidade total de água na camada de 0-40 cm, para a face de exposição das plantas voltadas ao sul (Tabela 2).

Meireles et al. (2001) estudaram a infestação do BMC sobre diferentes níveis de déficit hídrico em casa de vegetação. Segundo os autores, existem maiores infestações do inseto-praga em plantas submetidas à maior déficit hídrico. Entretanto, o fato de ocorrer menor infestação do BMC no tratamento não irrigado assim como no manejo de irrigação ' $B$ ' pode estar associado ao menor enfolhamento das parcelas experimentais.

Dessa forma, plantas mais enfolhadas podem ter favorecido a maior infestação do BMC nos manejos de irrigação ' $C$ ', ' $D$ ' e 'E'. Ainda, Avilés (1991) estudou a flutuação populacional do BMC na Zona da Mata mineira. Segundo o autor, a infestação do BMC é maior nos ramos situados na face de exposição norte em relação aos ramos da face sul. Justifica-se assim maior incidência do inseto-praga na face de exposição das plantas voltadas ao norte nos manejos de irrigação 'A' e 'B'.

Conforme Parra \& Nakano (1976), no período seco do ano ou chuvoso, as folhas do cafeeiro expostas ao sol são mais favoráveis à ocorrência do inseto-praga.

Dessa forma, a ocorrência de menor exposição à luz solar associada a temperaturas amenas na face de exposição sul da planta, sombreada, provavelmente contribuí no incremento do período de molhamento foliar no cafeeiro (Caramori et 
Tabela 1. Resumo da análise de variância em parcelas sub-subdivididas da incidência porcentual de folhas minadas (FM) por Leucoptera coffeella em cafeeiro irrigado por gotejamento.

\begin{tabular}{lcc}
\hline \hline \multirow{2}{*}{ Fonte de Variação } & GL & QM e Significância \\
\hline Bloco & 3 & FM \\
Manejo (M) & 4 & 0,0525490208 \\
Resíduo (a) & 12 & $0,0393684747^{*}$ \\
\hline (Parcelas) & 19 & 0,0114294307 \\
\hline Face (F) & 1 & - \\
M x F & 4 & $0,1392197694^{* *}$ \\
Resíduo (b) & 15 & $0,0425091793^{*}$ \\
\hline (Subparcela) & 39 & - \\
\hline Épocas (E) & 11 & 0,0125642844 \\
M x E & 44 & 0,0070138729 \\
F x E & 11 & 0,0128863216 \\
M x F x E & 44 & 0,0094637797 \\
Resíduo (c) & 330 & 0,0081927965 \\
\hline (Sub-subparcela) & 479 & - \\
\hline CV (\%) Manejos & & 12,75 \\
CV (\%) Faces & & 13,37 \\
CV (\%) Épocas & & 10,80 \\
\hline \hline
\end{tabular}

"Significativo a $1 \% ;{ }^{* *}$ Significativo a $5 \%$. Dados estatísticos transformados em Log $(\mathrm{x}+0,5)$.

Tabela 2. Porcentagem de folhas minadas (FM) por Leucoptera coffeella nos manejos da irrigação, com a face de exposição do cafeeiro voltada ao norte e ao sul.

\begin{tabular}{llc}
\hline \hline \multirow{2}{*}{ Fonte de Variação } & \multicolumn{2}{c}{ FM $(\%)$} \\
\cline { 2 - 3 } & Face Norte & Face Sul \\
\hline Manejo A (Testemunha) & 2,12 aA & 1,18 abB \\
Manejo B & 2,82 aA & $1,16 \mathrm{bB}$ \\
Manejo C & 2,94 aA & 2,31 aA \\
Manejo D & 2,13 aA & 2,23 aA \\
Manejo E & 2,32 aA & 2,33 aA \\
\hline \hline
\end{tabular}

Médias seguidas pela mesma letra, minúscula nas colunas que comparam o manejo dentro de cada face e maiúscula nas linhas que comparam a face dentro de cada manejo, não diferem entre si pelo teste de Tukey (5\%). Dados estatísticos transformados em $\log (\mathrm{x}+0,5)$.

al., 1996; Santos et al., 2008), o que pode ter desfavorecido o BMC.

Esse fato possivelmente resultou em condições microclimáticas desfavoráveis ao BMC, devido o menor ressecamento das folhagens. Os resultados obtidos no presente estudo concordam com os observados por Custódio et al. (2009) em mesma área experimental. Segundo os autores, houve influência significativa de lâminas de irrigação por aspersão, tipo pivô central, apenas para a face de exposição norte das plantas devido provavelmente à maior radiação solar direta condicionar um microclima favorável à incidência do BMC.

A influência da face de exposição da planta na infestação de insetos-praga também foi observada por pesquisadores, na Terra do Fogo, no extremo sul $\left(58^{\circ} \mathrm{Sul}, 68^{\circ}\right.$ Oeste) da Argentina (Rousseaux et al., 2004). Os autores relatam que a qualidade de folhas e a herbivoria por insetos fitófagos foram afetadas pela face de exposição norte e sul, em árvores de Nothofagus antartica. 
Segundo os autores, ocorreu maior número de lesões por folha e maior consumo de área foliar por insetos herbívoros (Lepidoptera: Geometridae e Coleoptera: Chrysomelidae e Curculionidae), além de maior concentração de flavonóides e ácido gálico, nos ramos orientados para a face sul das plantas devido à menor radiação solar incidente. Observase, portanto, a influência determinante da radiação solar sobre a ocorrência de diferentes insetos-praga.

Entretanto, os resultados do presente estudo discordam dos observados por Custódio et al. (2009) quando os autores mencionam que houve maior incidência do BMC no tratamento não irrigado $(11,24 \%)$ e menor nos tratamentos irrigados. Citam os autores que houve redução da infestação do inseto-praga com o incremento de maiores lâminas de irrigação por pivô central, sendo registrada menor incidência $(6,52 \%)$ na maior lâmina de irrigação, de $140 \%$ da evaporação do tanque classe 'A' (ECA). Dessa forma, em lavoura irrigada por gotejamento sob diferentes manejos, provavelmente houve mínima influência do fornecimento da água na projeção da copa das plantas, a ponto de ocasionar grandes modificações microclimáticas para afetar a infestação do BMC.
Houve maior infestação do BMC na época seca do ano entre abril e outubro, sendo registrada incidência máxima de $4,04 \%$, comparada à época chuvosa entre novembro e março, na qual foi observada incidência máxima de $1,50 \%$ (Tabela 3). Trabalhos mencionam que a ocorrência do BMC está condicionada a fatores climáticos assim como ao sistema de condução da lavoura (Reis \& Souza, 1986). Portanto, os resultados obtidos são justificados pelos menores índices pluviométricos registrados entre abril e outubro, que possivelmente teriam favorecido a infestação do insetopraga (Figura 1). Segundo Villacorta (1980), foi observado no estado do Paraná que na cultivar Mundo Novo a população do BMC é influenciada principalmente pelo regime pluviométrico, sendo responsável por ocasionar grande mortalidade do insetopraga.

Ainda, os resultados obtidos no presente estudo concordam com os observados por Nascimento (2002) em três cultivares de Coffea arabica L. na região de Monte Alto (SP). Cita o autor que o BMC é mais abundante de abril até o início de junho.

Tabela 3. Incidência porcentual de folhas minadas (FM) por Leucoptera coffeella em cafeeiro irrigado por gotejamento em diferentes épocas do ano (EA), no período de março de 2009 a fevereiro de 2011. UFLA, Lavras, MG, 2011.

\begin{tabular}{|c|c|c|c|c|c|c|c|c|c|c|c|c|}
\hline & 1 & 2 & 3 & 4 & 5 & 6 & 7 & 8 & 9 & 10 & 11 & 12 \\
\hline EA & $\underset{0}{3}$ & 忌 & $\frac{3}{0}$. & $\bar{\Xi}$ & $\stackrel{\Xi}{\sigma}$ & $\begin{array}{l}\vec{D} \\
00 \\
0 \\
0 \\
0 \\
0\end{array}$ & $\begin{array}{l}\widetilde{Q} \\
\mathbb{0} \\
\overrightarrow{0} \\
\vec{\Xi} \\
0\end{array}$ & 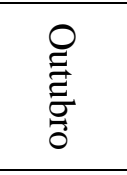 & $\begin{array}{l}Z \\
Z \\
0 \\
0 \\
0 \\
\Xi \\
0 \\
0 \\
\end{array}$ & $\begin{array}{l}\nabla \\
\mathbb{D} \\
0 \\
0 \\
0 \\
0 \\
0 \\
0\end{array}$ & 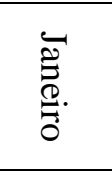 & $\begin{array}{l}T \\
T \\
Q \\
0 \\
0 \\
0 \\
0 \\
0\end{array}$ \\
\hline F M & $1,50 \mathrm{~cd}$ & $3,54 a b$ & $2,35 b c$ & $2,75 b c$ & $4,04 a$ & $3,03 \mathrm{ab}$ & $2,78 b$ & $2,32 b c$ & $1,00 \mathrm{~d}$ & $0,81 \mathrm{~d}$ & $1,16 \mathrm{~d}$ & $0,60 \mathrm{~d}$ \\
\hline
\end{tabular}

Médias seguidas na linha pela mesma letra, não diferem entre si, pelo teste de Tukey (5\%) 


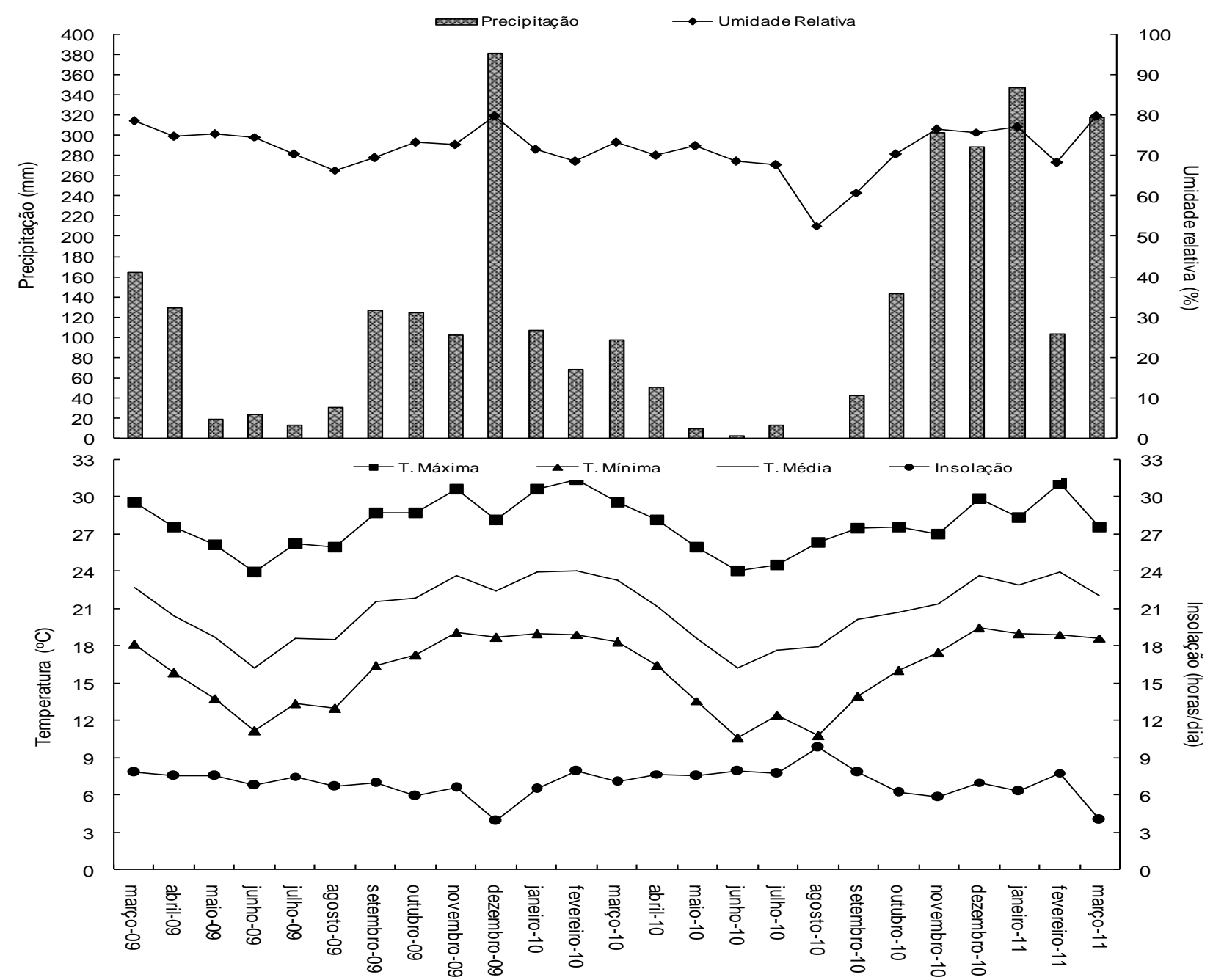

Figura 1. Variáveis climatológicas mensais no período de março de 2009 a março de 2011.

Com base nos resultados apresentados, pode-se observar que durante o período de avaliação do BMC, entre março de 2009 e março de 2011, foram registrados baixos índices de folhas minadas, sempre inferiores a $5 \%$ de incidência, em lavoura irrigada por gotejamento. Conforme também observado por Custódio et al. (2009) no sul de Minas Gerais, entre abril de 2004 e março de 2006, a realização de amostragens para o monitoramento fitossanitário do cafezal é importante para a tomada da decisão quanto ao controle químico, pois muita das vezes poderá ser desnecessária a aplicação de inseticidas, uma vez que o índice populacional do BMC pode estar muito abaixo do nível de dano econômico, por estar sendo controlado naturalmente por agentes bióticos e abióticos. Entretanto, devido à baixa incidência do BMC, novos estudos serão necessários para determinar o efeito da irrigação por gotejamento no manejo dessa praga.

\section{CONCLUSÕES}

Há menor incidência do bichomineiro na face de exposição das plantas voltadas ao sul quando na ausência de irrigação ou realizando a irrigação durante todo o ano sempre que o teor da água disponível no solo atinge $25 \%$ da disponibilidade total na camada de $0-40 \mathrm{~cm}$. 
Há maior incidência do bicho-mineiro na época de menor pluviosidade, entre abril e outubro.

\section{AGRADECIMENTOS}

Ao Departamento de Engenharia da UFLA, por disponibilizar a área experimental. Ao Conselho Nacional de Pesquisas e Desenvolvimento Tecnológico e ao Consórcio Brasileiro de Pesquisas e Desenvolvimento do Café, por fomentar a execução do estudo.

\section{REFERÊNCIAS BIBLIOGRÁFICAS}

AGRIANUAL. 2011. Anuário da Agricultura Brasileira. São Paulo: FNP Consultoria e Agroinformativos, $482 \mathrm{p}$.

AVILÉS, D. P. 1991. Avaliação das populações do bicho-mineiro do cafeeiro Perileucoptera coffeella (Lepidoptera: Lyonetiidae) e de seus parasitóides e predadores: metodologias de estudo e flutuação estacional. 127p. Dissertação (Mestrado em Entomologia) Universidade Federal de Viçosa, 1991.

BARBOSA, J.C.; MALDONADO JR, W. 2010. AgroEstat - Sistema para análise estatística de ensaios agronômicos. versão 1.0.

CARAMORI, P. H.; ANDROCIOLI. A.; LEAL.; A. C. 1996. Coffee shade with Mimosa scabrella Benth. for frost protection in southern Brazil. Agroforestry Systems, Dorbrecht , v. 33, p. 205-214.

COELHO, G.; SILVA, A.M; REZENDE, F.C.; SILVA, R.A.; CUSTÓDIO, A.A.P. 2009. Efeito de épocas de irrigação e de parcelamentos de adubação sobre a produtividade do cafeeiro 'Catuaí'. Ciência e Agrotecnologia, Lavras, v.33, p.67-73.

CUSTÓDIO, A.A.P. 2009. Manejo da irrigação na lavoura cafeeira (Coffea arabica L.) recepada. $85 \mathrm{p}$. Dissertação
(Mestrado em Engenharia Agrícola) Universidade Federal de Lavras, Lavras, 2009.

CUSTÓDIO, A. A. de P.; MORAES, J. C.; CUSTÓDIO, A. A. de P.; LIMA, L. A.; FARIA, M. A. de; GOMES, N. M. 2009. Incidência do bicho-mineiro do cafeeiro em lavoura irrigada sob pivô central. Coffee Science, Lavras, v.4, p. 16-26.

GALLO, D; NAKANO, O; SILVEIRA NETO, S; CARVALHO, R. P. L.; BAPTISTA, G. C.; BERTI FILHO, E.; PARRA, J. R. P.; ZUCCHI R A.; ALVES, S. B.; VENDRAMIM, J. D.; MARCHINI, L. C.; LOPES, J. R. S.; OMOTO, C. 2002. Entomologia agrícola, Piracicaba: FEALQ, 920 p.

GRAVENA, S. 1983. Táticas de manejo integrado do bicho mineiro do cafeeiro Perileucoptera coffeella (GuérinMèneville, 1842): I - Dinâmica populacional e inimigos naturais. Anais da Sociedade Entomológica do Brasil, v.12, p.61-71.

LIMA, L. A.; CUSTÓDIO, A. A. P.; GOMES, N.M. 2008. Produtividade e rendimento do cafeeiro nas cinco primeiras safras irrigado por pivô central em Lavras, MG. Ciência e Agrotecnologia, Lavras, v.32, p.18321842.

MEIRELES, D. F. de; CARVALHO, J. de A.; MORAES, J. C. 2001. Avaliação da infestação do bicho-mineiro e do crescimento do cafeeiro submetido a diferentes níveis de déficit hídrico. Ciência e Agrotecnologia, Lavras, v. 25, p. 371374.

NASCIMENTO, A. F. 2002. Dinâmica populacional de Leucoptera coffeellum (Guérin-Mèneville, 1842) (Lepidoptera: Lyonetiidae) em cafeeiros e Phyllocnistis citrella Stainton $1856 \quad$ (Lepidoptera: Gracillariidae) em citros e ocorrência de parasitóides. 65p. Dissertação (Mestrado em Entomologia Agrícola) - 
Universidade Estadual Paulista, Faculdade de Ciências Agrárias e Veterinária, Jaboticabal.

PARRA, J. R. P.; NAKANO, O. 1976. Determinação do nível de dano econômico de Perileucoptera coffeella (Guérin-Mèneville, 1842) (Lepidoptera Lyonetiidae). In: CONGRESSO BRASILEIRO DE PESQUISAS CAFEEIRAS, 4, Caxambu, 1976. Resumos... Rio de Janeiro: IBC/ GERCA, p. 1.

REIS, P. R.; SOUZA, J. C. 1986. Influência das condições do tempo sobre as populações de insetos e ácaros. Informe Agropecuário, Belo Horizonte, v. 12, p. 25-30.

REIS, P. R.; SOUZA, J.C.; RIGITANO. 1998. Manejo integrado das pragas do cafeeiro em Minas Gerais. Informe Agropecuário, Belo Horizonte, vol. 19, p. 17-25.

RIBEIRO, A. C.; GUIMARÃES, P. T.; ALVAREZ, V. H. V. 1999. (Ed). Recomendações para o uso de corretivos e fertilizantes em Minas Gerais. Viçosa: Comissão de Fertilidade do solo do Estado de Minas Gerais, 359p. ROUSSEAUX, M. C.; JULKUNENTIITTO, R.; SEARLES, P. S.; SCOPEL, A. L.; APHALO, P. J.; BALLARÉ, C. L. 2004. Solar UV-B radiation affects leaf quality and insect herbivory in the southern beech tree Nothofagus antarctica. Oecologia, Rio de Janeiro, v. 138, p. 505-512.

SANTINATO, R.; FERNANDES, A. L. T.; FERNANDES, D. R. 2008. Irrigação na cultura do café. 2.ed. Campinas: $\mathrm{O}$ Lutador, $476 \mathrm{p}$.

SANTOS, E. A.; SENTELHAS, P. C.; PEZZOPANE, J. E. M.; ANGELOCCI, L. R.; MONTEIRO, J. E. B. A. 2008. Spatial variability of leaf wetness duration in cotton, coffee and banana crop canopies Scientia Agricola, Piracicaba, v. 65, p. 18-25,
SOUZA J. C., REIS P. R., RIGITANO R.L. O. 1998. Bicho-mineiro-do-cafeeiro: biologia, danos e manejo integrado. 2 ed., Belo Horizonte, Epamig, 48p. (EPAMIG, Boletim Técnico, 54).

VILLACORTA, A. 1980. Alguns fatores que afetam a população estacional de Perileucoptera coffeella GuérinMèneville, 1842 (Lepidoptera: Lyonetiidae) no norte do Paraná, Londrina, PR. Anais da Sociedade Entomológica do Brasil, v.9. p. 23-32.

ZAMBOLIM, L.; SOUZA, A. F.; MANTOVANI, E. C. 2007. Influência da irrigação no progresso de doenças e pragas do cafeeiro. ITEM - Irrigação \& Tecnologia Moderna, Brasília, n. 73, p. 67-76. 